\title{
Arte, Corpo, Cidade: Sobre Elefantes e Pessoas em Situação de Rua
}

\author{
Natália Alves dos Santos ${ }^{1}$ \\ ${ }^{1}$ Universidade Federal de Santa Catarina, SC, Brasil.
}

\author{
Andréa Vieira Zanella ${ }^{1}$ \\ ${ }^{1}$ Universidade Federal de Santa Catarina, SC, Brasil.
}

\begin{abstract}
Resumo: $\mathrm{O}$ desafio de traduzir e analisar uma experiência estética, vivenciada na condição de espectadora da peça Protocolo Elefante, motiva a escrita deste artigo. O espetáculo integra o projeto homônimo do grupo de dança contemporânea Cena 11, que se dedica a pesquisar o modo de controle do corpo, partindo da noção de um corpo que é, ao mesmo tempo, singular e coletivo. Com a figura do elefante, protagonista do espetáculo, objetivamos discutir a condição de pessoas em situação de rua e algumas das tensões que emergem do encontro de seus corpos com o corpo da cidade. Concluímos, por meio dessa experiência estética, que Protocolo Elefante explicitou violências protocolares que aviltam a vida de maneiras variadas, como vemos acontecer cotidianamente com pessoas em situação de rua nas cidades.
\end{abstract}

Palavras-chave: Corpo, Arte, Cidade, Pessoas em Situação de Rua, Psicologia Social.

\section{Art, Body, City: On Elephants and Homeless People}

\begin{abstract}
This study was prompted by the challenge of translating and analyzing an aesthetic experience, as an Elephant Protocol dance show spectator. The performance is part of the homonymous project by contemporary dance group Cena 11, dedicated to researching how the body is controlled, based on a body that is, at the same time, singular and collective. Using the image of the elephant, main of the show, we discuss the condition of homeless people and some of the tensions that emerge when their bodies encounter the city's body. Through this aesthetic experience, we conclude that Elephant Protocol specifies the protocol violence that demeans life in various ways, as we see happen daily with homeless people living in the cities.
\end{abstract}

Keywords: Body, Art, City, Homeless People, Social Psychology.

\section{Arte, Cuerpo, Ciudad: Sobre Elefantes y Personas en Situación de Calle}

Resumen: El desafío de traducir y analizar una experiencia estética vivenciada en la condición de espectadora de la pieza Protocolo Elefante es lo que motiva la escritura de este artículo. El espectáculo integra el proyecto homónimo del grupo de danza contemporánea Cena 11, grupo que se dedica a investigar el modo de control del cuerpo partiendo de la noción de un cuerpo que es a la vez singular y colectivo. Con la figura del elefante, protagonista del espectáculo, nos proponemos discutir la condición de personas en situación de calle y algunas de las tensiones que emergen del encuentro de sus cuerpos con el cuerpo de la ciudad. A partir de esa experiencia estética, concluimos que el Protocolo Elefante explicitó violencias de protocolos que degradan la vida de variadas maneras como sucede cotidianamente con las personas en situación de calle en las ciudades.

Palabras clave: Cuerpo, Arte, Ciudad, Personas en Situación de Calle, Psicología Social. 


\section{Introdução}

Tudo começa pelo abismo. Gilles Deleuze

Começamos esta escrita com o anúncio de um abismo para pensar a experiência que nos colocou diante da fragilidade da existência humana. Segundo o Dicionário Houaiss da Língua Portuguesa, a palavra abismo, dentre outros significados, diz respeito à abertura cujo fundo é geralmente desconhecido; lugar profundo, íngreme; despenhadeiro, precipício, ribanceira; tudo que é imenso; profundidade sem termo; imensidão, infinito, vastidão; tudo que é misterioso, enigma, incógnita; grande distância, separação incontornável, distanciamento, separação; situação de extrema dificuldade, condição insustentável (Houaiss \&Villar, 2009). E de que abismo falamos aqui?

Trata-se da experiência estética vivenciada durante a III Semana da Dança da Universidade Federal de Santa Catarina (UFSC), no início do mês de junho de 2017, quando a primeira autora teve a oportunidade de assistir ao espetáculo Protocolo Elefante, da companhia de dança Cena 11 (2017). Radicado na cidade de Florianópolis, Santa Catarina, o grupo Cena 11 atua há 22 anos e é referência nacional e internacional no cenário de produção artística de dança contemporânea.

O espetáculo evidencia uma estética presente na cena artística contemporânea: não a estética do belo, mas aquela que tem como função primordial desterritorializar, tirando a(o) espectadora(o) do terreno habitual ou zona de conforto, fazendo-a(o) repensar a existência, provocando tensionamentos e convocando a respostas na esfera da vida.

Embora já tenha vivenciado momentos em que tal fragilidade fora escancarada, este tocou a espectadora/ pesquisadora de maneira ímpar. Talvez por remeter ao que a mobilizou a desenvolver uma pesquisa de doutorado: a $\mathrm{RUA}^{1}$ e as pessoas que fazem dela sua morada ou meio de sobrevivência; uma pesquisa que elege como protagonistas e foco do olhar outras pessoas que habitam o "entre", ou melhor, os "espaços intermediários em torno da cidade, na sua margem" (Careri, 2013, p. 14). “Estar 'entre’ não quer dizer ser uma coisa ou outra, quer dizer ser temporariamente uma coisa e outra. Estar no meio de [en train de]. . .
Em transformação. É não somente estar no meio ou em um meio, mas ser o próprio meio. .." (Descartes, 1997 citado por Careri, 2013, p. 10).

Os espaços intermediários pesquisados são ao mesmo tempo conhecidos e desconhecidos, familiares e estranhos, assim como as pessoas que os habitam e se configuram como "outros", pessoas que fazem das ruas das cidades suas moradas, permanentemente ou não e em condições variadas. Pessoas que transitam anonimamente à luz do dia, mescladas à multidão que circula freneticamente, e que permanecem quando o ruído do comércio e das repartições cessa ao final do expediente. Nas ruas de poucos passantes, nas praças e marquises de iluminação fugidia, assentam os poucos pertences que escondem durante o dia, e se deixam levar pelo ritmo da paisagem, afirmando suas presenças na vida da cidade. São como os infames pesquisados por Michel Foucault (2016, p. 207): "vidas destinadas a passar por baixo de qualquer discurso e a desaparecer sem nunca terem sido faladas".

Tal como o elefante personificado pelos(as) integrantes do espetáculo, as pessoas em situação de rua criam estratégias ímpares para sobreviver às armadilhas do cotidiano. À medida em que seus corpos padecem, tentando resistir à imposição de uma vida que não lhes pertence, ou que a eles não faz sentido algum, afastam-se da manada, da multidão, e enfeitam seus corpos com os poucos objetos e histórias que os acompanharam ao longo de suas vidas.

Assumimos, com esta escrita, ao olhar para estes corpos e para o elefante do espetáculo, um duplo desafio: o primeiro é traduzir uma experiência estética, singular, vivenciada na condição de espectadora de uma apresentação de dança, para outra linguagem, a escrita. Paulo Bezerra (2012) afirma que a tradução não deixa de ser um movimento de criação, uma vez que o tradutor:

. . sempre é levado a escarafunchar os desvãos de sua língua, sua riqueza vocabular, seu manancial de ditos e provérbios, suas formas de linguagem gestual, enfim, seus múltiplos recursos semânticos e morfossintáticos na tentativa de resolver problemas similares que o original lhe impõe. Ele sabe que trabalha com uma obra acabada, que precisa dar nova vida a essa obra, precisa

${ }^{1}$ Utilizamos o termo RUA em caixa alta para destacar a forma potente com que a rua mobiliza a primeira autora e a convoca a pesquisar a temática das pessoas em situação de rua. 
realizar uma operação de Caronte, para usar uma metáfora de Topior, mas de tal forma que as personagens do barco-texto não percam a memória e a obra atravesse a contento o seu Estige, chegando viva à outra margem: à língua e à cultura de chegada, do tradutor. Para construir essa travessia, o tradutor tem de passar por um processo criador semelhante ao vivido pelo autor do original, guardadas, é claro, as devidas diferenças e especificidades (Bezerra, 2012, p. 47).

A tradução que aqui apresentamos é uma ponte a lançar a(o) leitora(o) em direção a outra experiência, em outro contexto: a condição de pessoas em situação de rua, a partir de algumas das tensões que emergem do encontro de seus corpos com o corpo da cidade.

O segundo desafio, que ao primeiro está diretamente amalgamado, consiste em analisar essas tensões para que a leitura deste trabalho possa se configurar como uma abertura do corpo leitor para o encontro com corpos outros, para que se possa compreender a experiência das pessoas em situação de rua em direta relação com a nossa própria existência. Pensemos, portanto, nessa abertura como uma problematização do direito de existir ou como um convite aos seguintes questionamentos: "o que resta a um ser quando seu modo de existência é contestado? Que espaço-tempo ele ainda pode ocupar legitimamente?" (Lapoujade, 2017, p. 24).

\section{Grupo Cena 11 e o processo de criação do Projeto Protocolo Elefante}

O espetáculo Protocolo Elefante conclui o projeto homônimo do grupo Cena 11, desenvolvido desde 2014. Foi contemplado pelo Prêmio Funarte de Dança Klauss Vianna (2014) e realizado com o apoio do Governo do Estado de Santa Catarina, por meio da Secretaria de Estado de Turismo, Cultura e Esporte, da Fundação Catarinense de Cultura, Fundo Estadual de Incentivo à Cultura (Funcultural) e Edital Elisabete Anderle $^{2}$ de Santa Catarina (2014). No corpo de dançarinos estavam Karin Serafin, Mariana Romagnani, Aline Blasius, Marcos Klahn, Edu Reis Neto, Natascha Zacheo, Jussara Belchior e Hedra Rockenbach, que também assinava a direção de trilha sonora e iluminação.
No site $^{3}$ da companhia é possível encontrar algumas pistas da trajetória do grupo. O objeto de pesquisa central do Cena 11 é o modo de controle do corpo, partindo da noção de um corpo que é, ao mesmo tempo, singular e coletivo, "um corpo impossível de se compreender a sós” (Cena 11, 2018).

Alejandro Ahmed, responsável pela criação, direção e coreografia do espetáculo, afirma que o grupo defende a ideia de uma dança em função do corpo, ao invés de exigir do corpo um pertencimento a alguma linguagem específica. E acrescenta: "no corpo vamos encontrar as condutas de mover capazes de, de alguma forma, traduzirem a realidade que estamos interessados em comunicar publicamente" (TV em Cartaz, 2017).

Essa noção de uma dança em função do corpo remete à análise empreendida pelo filósofo Gilles Deleuze sobre algumas obras do pintor irlandês Francis Bacon. No trabalho intitulado Francis Bacon: lógica da sensação, Deleuze (2007) conduz ao movimento traçado pelo artista, que transgrediu o caráter meramente representativo de uma obra, irrompendo as fronteiras da figuração e privilegiando a Figura. Nas palavras de Maurício Mangueira e Eduardo Maurício (2012), interlocutores de Deleuze:

A figuração em pintura diz respeito exatamente a certa concepção, a certo modo de pensar: o representacional. Ela ocorre quando os vários elementos de uma tela, suas várias figuras e objetos, se dispõem de modo a pretender representar uma história, a ilustrar uma narrativa. Por outro lado, privilegiar a Figura seria, pelo menos em um primeiro momento, isolá-la, fazendo com que seja rompido o liame representativo existente entre ela e o resto da pintura. Assim, aquilo que parece estar sempre em evidência na obra de Bacon é justamente isto: como escapar da representação na pintura ou como liberar a pintura de um caráter predominantemente representativo (Mangueira \& Maurício, 2012, p. 155).

É possível perguntar: a proposta de trabalho do Cena 11, analogamente ao movimento realizado por Francis Bacon ao pintar seus quadros, seria a "de tornar visíveis as diferentes forças que agem nos

\footnotetext{
${ }^{2}$ Mais informações podem ser encontradas no endereço: https://elisabeteanderle.idcult.com.br/

${ }^{3} \mathrm{O}$ site da Companhia Cena 11 pode ser acessado por meio do link: https://www.cenall.com.br/
} 
corpos, modificando-os, provocando-lhes alterações?" (Mangueira \& Maurício, 2012, p. 155). Estariam essas(es) bailarinas(os) evidenciando ao público a existência de um outro corpo, de um Corpo sem Órgãos (CsO)? (Deleuze \& Guattari, 2012).

Deleuze e Guattari se apropriam da noção de $\mathrm{CsO}$, originalmente cunhada por Antonin Artaud ${ }^{4}$, e apresentam esse corpo como o que está além do organismo, mas que é também limite do corpo vivido. Aos autores não interessava definir um corpo, explicar o que era ou não um corpo, mas tratá-lo em sua corporeidade - que sustenta as forças incorporais estabelecidas nas relações.

O CsO, então, está no campo da potência, dá consistência aos fluxos da vida e se abre às multiplicidades (Santos, 2010, p. 58). "O corpo sem órgãos se opõe menos aos órgãos do que à organização dos órgãos que se chama organismo. É um corpo intenso, intensivo. . . não tem órgãos, mas limiares ou níveis" (Deleuze, 2007, p. 52).

Deleuze e Guattari (2012) propõem uma concepção do corpo que não corresponde a um despedaçamento dos órgãos vitais, mas que nos permite pensar o modo de individuação corporal antes de sua organização centrada, isto é, sem um centro organizador unificante e hierarquizante do corpo e, a partir disso, "reformular a concepção do vital, ao criticar o modelo político da organização de um poder centrado, unitário, soberano, que submete o corpo a um modelo hierárquico das funções vitais" (Damasceno, 2017, p. 141). Partimos dessa noção de corpo para discutir o projeto Protocolo Elefante.

O projeto foi dividido em cinco etapas, intituladas pela companhia de autorretrato, espelho, êxodo/ solilóquio, reencontro/acontecimento e residências. A proposta da etapa inicial foi a análise e Autorretrato daquilo que o grupo é quando se reúne, trabalhando juntos por quatro meses para elaborar o que chamaram de autorreferência. Segundo Ahmed, essa fase do projeto é constante no grupo, "o autorretrato é um lugar onde estamos nos perguntando quem somos e, de certa forma, reivindicando quais são as origens do que a gente faz" (Cena 11, 2016).

A etapa Espelho, de auto reconhecimento a partir do olhar alheio, consistiu no encontro, em momentos distintos, com os artistas Eduardo Fukushima ${ }^{5}$, Michelle Moura ${ }^{6}$ e Wagner Schwartz ${ }^{7}$ que estão relacionados com as áreas de investigação do grupo para as questões de design de movimento, uma escolha nada aleatória. O objetivo dessa etapa foi "ver quem você é para aquele que não é você, perguntar a outra pessoa quem ela pensa que você é. Assim, ela pode tanto revelar coisas que estão adormecidas em sua percepção quanto retificar outras que você percebe" (Cena 11, 2016). Cada convidado(a) pôde intervir na rotina de ensaios da companhia durante dez dias, propondo inúmeras atividades, como ações performativas e conversas sobre o treinamento do grupo.

O terceiro estágio, êxodo/solilóquio, propôs o afastamento do elefante, permitindo aos(às) artistas que se encontrassem consigo mesmos(as), isolando-se em diferentes partes do mundo para conviverem com outras culturas e rotinas. Essa imersão solitária propiciou momentos de autoinvestigação, essenciais ao reconhecimento dos vestígios pessoais que compuseram o todo construído em grupo. Além disso, essa etapa deu origem ao livro Rumor, produzido em parceria com o artista Pedro Franz ${ }^{8}$. Êxodo muito se aproxima do movimento nômade dos elefantes, que precisam se deslocar frequentemente em busca de alimento, já que comem mais de 100 quilos de plantas por dia. Entretanto, esse movimento nem sempre diz respeito à busca por comida; a senilidade, por exemplo, faz com que os elefantes se afastem da manada, já que não conseguem mais acompanhar seu ritmo, chegando a criar grupos que se isolam em função da velhice, e lá permanecem até morrer.

Já em reencontro/acontecimento, a companhia se reuniu uma única vez para discutir esse isolamento vivenciado pelos(as) integrantes: uma partilha de experiências aberta ao público.

\footnotetext{
${ }^{4}$ Antoine Marie Joseph Artaud, mais conhecido como Antonin Artaud, foi um dramaturgo, poeta, ator, escritor, roteirista e diretor de teatro. Nasceu em Marselha, na França, no ano de 1956 e faleceu aos 51 anos.

${ }^{5}$ Eduardo Fukushima é paulista, coreógrafo, dançarino e professor de Tai Chi Chuan.

${ }^{6}$ Michelle Moura é dançarina e coreógrafa catarinense, residente em Berlim. Os registros de sua obra e relato da trajetória da artista estão disponíveis no site https://michellemoura.com/sobre/

7 Wagner Miranda Schwartz nasceu no estado do Rio de Janeiro, é performer, coreógrafo e escritor. Seu endereço eletrônico é https://www.wagnerschwartz.com/

${ }^{8}$ Pedro Franz é um quadrinista catarinense e colaborador da Revista Piauí. Mais informações sobre o artista e suas obras estão disponíveis em http://www.pedrofranz.com.br/
} 
Residências, etapa que aconteceu em Dusseldorf, Alemanha; na Bienal Sesc de Dança, em Campinas; e no Sesc Consolação, em São Paulo, proporcionou aos(às) artistas "aprenderem a aprender de novo" (TV em Cartaz, 2017).

Cada uma das etapas integrou o que o grupo tenta fazer a cada novo projeto: reinventar sua forma de aprender. Movimento-exotopia ao promover um distanciamento fundamental para o processo de criação artística, dando o chamado excedente de visão. O conceito de exotopia, cunhado pelo teórico russo Mikhail Bakhtin, está relacionado à:

ideia de acabamento, de construção de um todo, o que implica sempre um trabalho de fixação e de enquadramento, como uma fotografia que paralisa o tempo. O espaço é a dimensão que permite fixar, inscrever o movimento ou, dito de outra forma, a dimensão em que o movimento pode se escrever e deixar suas marcas. A fixação é resultado de todo trabalho de objetivação, seja científico ou artístico, pois esse trabalho distingue dois sujeitos e duplica seus respectivos lugares: o daquele que vive no instante e no puro devir e o daquele que lhe empresta um suplemento de visão por estar justamente de fora. Por mais provisória que possa ser a objetivação produzida, ela implica sempre o extrair-se do puro movimento (Brait, 2016, pp. 100101).

A peça Protocolo Elefante, resultado do projeto relatado, gira em torno de um questionamento: por que e para que continuar? Segundo Alejandro Ahmed, em entrevista concedida ao canal TV em cartaz $^{9}$ no Youtube, tal pergunta surgiu quando o grupo refletia sobre a própria continuação como companhia de dança independente (TV em Cartaz, 2017).

Ao contar sobre o processo de criação do projeto, o diretor diz que um dos objetivos do trabalho é mostrar ao público o corpo "enquanto algo que comunica", e acrescenta: "nenhuma presença pode ser inofensiva. .. que nenhum de nós seja amortecido ou inofensivo para pensar um mundo novo" (TV em Cartaz, 2017).

Protocolo Elefante "evoca . . . um réquiem-nascimento na tensão entre o esquecimento e novos futuros . . . investiga na ação de afastamento e isolamento do elefante na iminência de sua morte uma metáfora de separação e exílio." (Grupo Cena 11, 2016).

\section{Sobre o protocolo, os elefantes e as pessoas em situação de rua}

$\mathrm{Na}$ condição de espectadora/pesquisadora, considero Protocolo Elefante uma peça-abismo por, dentre outros significados que tal palavra possa ter, nos convocar à separação da obra de arte de seu artífice, e para além de suas intenções e sentidos pressupostos. Sobre tal movimento, Vigotski (1999) já afirmara: "uma vez criada, a obra de arte separa-se de seu criador" (Vigotski, 1999, p. 17).

$\mathrm{Na}$ inesgotável diversidade da obra simbólica, isto é, de qualquer verdadeira obra de arte, está a fonte de suas múltiplas interpretações e enfoques. E a interpretação que lhes dá o autor é apenas mais uma dentro dessa multiplicidade de possíveis interpretações, que a nada obriga (Vigotski, 1999, p. 19).

Assistir à peça-abismo produziu em mim fissuras, rupturas sutis, deslizes de sentidos, uma experiência estética configurada em uma relação sensível, atenta aos murmúrios, baseada "no encontro que a funda como potência de afecção, como fagulha a provocar respostas, quiçá potentes ao ponto de também virem a se configurar como fagulhas a inflamar a própria vida" (Zanella, 2017, p. 19).

Em uma das cenas do espetáculo, cada bailarina(o) executa uma coreografia com bastões de metal - os mesmos bastões com que compõem diversos sons que ajudam a dar forma e estrutura ao enredo da peça. Cada movimento parece responder a um obstáculo proposto pelo bastão. Corpo e bastão, por vezes, coreografam disputas de espaço. Um desliza pela superfície do outro, se joga contra o outro, recua, se enfrenta. Corpo cilíndrico e corpo de carne me permitiram, através da experiência estética, deslocar o olhar e tensionar a forma de ocupação do espaço urbano pelas pessoas em situação de rua ${ }^{10}$. Movimentos diários de embate, que podem resultar em dor e morte.

\footnotetext{
${ }^{9}$ Disponível em: https://www.youtube.com/watch?v=SPrR66Y0lsE

${ }^{10}$ Sobre as estratégias de planejamento urbano e ocupação do espaço público que interferem nas vidas das pessoas em situação de rua, sugerimos a leitura de Carneiro (2019).
} 
A experiência estética proporcionada pela peça, possibilitou-me olhares outros sobre minha própria relação com o mundo e minha pesquisa acadêmica sobre pessoas em situação de rua e sua complexa relação com a cidade. Convocou-me a responder de algum modo à minha vida $\mathrm{e}$ a meus fazeres.

Solange Jobim e Sousa e Elaine Porto e Albuquerque (2013), ao mencionarem um dos escritos de Bakhtin, retomam o conceito de arquitetônica da respondibilidade do autor, nos advertindo de que não há como vivermos sem escapar da responsabilidade que nos cabe na unicidade de nossas vidas, pois "tudo o que pode ser feito por mim nunca será feito por ninguém mais" (Jobim e Sousa \& Porto e Albuquerque, 2013, p. 50). Ou seja, nossa existência é necessariamente conectada à existência de outras pessoas, nós nos vemos pelo olhar dos outros, nos compomos por meio desse olhar e precisamos dele para dar acabamento ao nosso viver. Como estamos, portanto, nos relacionando com esses outros que são tão caros à nossa existência?

Protocolo Elefante configurou-se, pois, em ferramenta para discutir as existências precarizadas das pessoas em situação de rua e os dispositivos que pretendem levá-las à morte em vida. Arte que nos convoca para uma temática política e que remete a pessoas que, nas tramas da cidade, "se transformam em vaga-lumes fugidios tentando se fazer tão discretos quanto possível, continuando ao mesmo tempo a emitir seus sinais" (Didi-Huberman, 2011, p. 17).

Já em seu início, o espetáculo anuncia ao público que todo corpo pode dançar. Sete artistas em cena, sete corpos completamente diferentes uns dos outros, corpos-vastos, corpos-outros, diferentes de tantos outros corpos dançarinos que já pude assistir, usando vestimentas pretas, roupas leves que facilitavam os movimentos que se alternavam entre a leveza/sutileza e a força, o embrutecimento. Cada corpo, em determinados momentos do espetáculo, empunhava um bastão de metal que ajudava a compor a trilha sonora, produzida ao vivo pelas(os) artistas. Daqueles bastões produziam-se diferentes sons, que se tornavam música com os gritos, gemidos, ruídos e balbuciar de suas bocas.

Partituras corporais eram cuidadosamente inventadas e propiciavam uma interação ímpar entre plateia e artistas. No decorrer do espetáculo, tais corpos despiam-se até chegarem à nudez, permanecendo apenas alguns adereços, delicadamente posicionados em suas cabeças, como aqueles que adornam muitos dos elefantes explorados para entretenimento de turistas.

O que teriam esses corpos despidos a nos dizer? São corpos que, como os das pessoas em situação de rua, resistem a toda e qualquer forma de engessamento e de aniquilamento de suas infinitas possibilidades de existência, de movimento. São "vagalumes que sofrem em seu próprio corpo uma eterna e mesquinha queimadura" (Didi-Huberman, 2011, p. 13). A presença desses corpos na cidade é uma resistência que "se apresenta no investimento e insistência em uma estética da existência, pautada em uma ética da diversidade da vida" (Zanella \& Furtado, 2012, p. 206). Mas essa diversidade não é propriamente bem quista: na cidade, os elefantes/pessoas destoam, pesam, são indesejados.

Corpos "em situação de rua" remetem àqueles que são diariamente silenciados pelas variadas estratégias que as cidades adotam para expulsá-los, entendendo-os como corpos estranhos à sua adequada tessitura-movimento. Na tensão diária com o corpo da cidade, esses corpos, por vezes, são despidos de seu direito de ir e vir. "Tal seria em todo caso, a 'glória miserável' dos condenados: não a grande claridade das alegrias celestiais bem merecidas, mas o fraco lampejo doloroso dos que se arrastam sob uma acusação e um castigo sem fim" (DidiHuberman, 2014, p. 13).

A presença de pessoas em situação de rua incomoda, seus corpos gritam como grita o elefante ao final da peça, em seu protocolo anunciado de morte, por meio dos corpos dançarinos feitos elefantes que, com seus bastões de metal, produziam ruídos de desespero. Uma súplica à cidade por sua continuidade enquanto parte de seu tecido, um clamor por seu não-desaparecimento. Mas nem sempre há espaço para esses gritos, "a cidade só é possível, do modo como a vivemos hoje, se o corpo e seus dejetos somem dos olhos" (Sousa \& Bechler, 2008, p. 396).

Ainda comum, a caça impiedosa aos elefantes, principalmente em alguns países da África, como Botsuana, para retirada de seu precioso marfim, muito se aproxima da "caça" promovida em algumas cidades a alguns de seus habitantes e seus modos de vida, com diferentes estratégias, sejam elas oficiais (planos diretores, legislações sobre ocupação do espaço urbano, dentre outras), não regulamentadas ou até mesmo proibidas.

Certamente as pessoas em situação de rua são algumas dessas vidas caçadas, transformadas em objetos indesejados, ruídos, restos, animais 
embrutecidos à mercê de caçadores. Muitas vezes tidas como insetos que, por nada oferecerem ao sistema capitalista, morrem à míngua como morreu o protagonista da obra A Metamorfose, de Franz Kafka (1915/2001), Sr. Gregor Samsa, após transformar-se em barata do dia para a noite, causando escândalo e repulsa em seu núcleo familiar.

A caça aos indesejados se materializa nas cidades de variadas formas, como mediante medidas higienistas que pretendem, literalmente, varrer de suas ruas os corpos que se atiram às calçadas. Forças que agem sobre os infames (Foucault, 2003), sobre os homens lentos (Santos, 1994), sobre pessoas ordinárias (Certeau, 1994), ninguéns (Galeano, 2005) e tantas outras nomeações que remetem aos que vivem/ existem pelas/nas ruas.

Tais pessoas incomodam, talvez por coreografarem cartas ímpares na urbe. As pessoas em situação de rua corpografam velocidades outras, nomadizam a experiência urbana, traçam circuitos diferenciados pela cidade, transitam e permanecem onde quase ninguém quer ficar/estar, desafiam a lógica urbana hegemônica. Um desafio que se produz pela mera existência e presença de seus corpos nas cidades.

A noção de corpografia permite pensar sobre o relacionamento entre corpo e cidade, por meio de toda e qualquer experiência humana. Segundo Fabiana Britto e Paola Jacques (2009), corpografias urbanas são "cartografias realizadas pelo e no corpo como registros corporais das experiências urbanas" (p. 346).

Uma ideia baseada na hipótese de que a experiência urbana inscreve-se, sob diversos graus de estabilidade, no próprio corpo daquele que a experimenta, e simultaneamente também configura sua corporalidade, mesmo que involuntariamente. As corpografias formulam-se como resultantes da experiência espaço-temporal que o corpo processa, relacionando-se com tudo o que faz parte do seu ambiente de existência: outros corpos, objetos, ideias, lugares, situações, enfim; e a cidade pode ser entendida como um conjunto de condições para essa dinâmica ocorrer. O ambiente (urbano inclusive) não é para o corpo meramente um espaço físico disponível para ser ocupado, mas um campo de processos que, instaurado pela própria ação interativa dos seus integrantes, produz configurações de corporalidade e ambiência (Britto, 2009, p. 14).

Que registros os corpos das pessoas em situação de rua carregam, quando se trata de sua relação com a cidade? Quais são seus protocolos? A que protocolos devem se submeter para permanecerem na urbe?

Podemos entender tanto o elefante em seu protocolo-projeto quanto as pessoas em situação de rua como produtores de movimentos diferenciados em cada um de seus contextos? Ou, tal qual David Lapoujade (2017) visibiliza a partir da obra de Etienne Souriau ${ }^{11}$, como existências plurais? "A primeira afirmação desse pluralismo é justamente que não há um único modo de existência para todos os seres que povoam o mundo, como também não existe um único mundo para todos esses seres" (Lapoujade, 2017, p. 14).

\section{Sobre tensões, corpos e cidade}

Atualmente, nas sociedades ocidentais, o modelo de cidade em que vivemos escancara um cotidiano da vida urbana que se aproxima do que Britto e Jacques (2009) chamam de processo de "espetacularização urbana", em alusão "às nefastas consequências do processo de privatização dos espaços públicos pela especulação imobiliária e a consequente gentrificação (enobrecimento de áreas com expulsão da população mais pobre) das cidades contemporâneas" (Britto \& Jacques, 2009, p. 338).

Paola Jacques (2012) acrescenta que o processo de espetacularização urbana está diretamente relacionado à pacificação do espaço público, que "busca esconder as tensões que são inerentes a esses espaços e, assim ... esterilizar a própria esfera pública, o que, evidentemente, esterilizaria qualquer experiência e, em particular, a experiência da alteridade nas cidades" (Jacques, 2012, p. 14). Há que se perguntar: quem tem o direito estar no espaço público e em que condições?

Na cidade-espetáculo ou cidade-cenário (Britto \& Jacques, 2009), quantos colchões já destruímos por ocuparem nossas praças? Quantos cobertores de pessoas em situação de rua já recolhemos por interromperem o tráfego, ao fazerem "montanhas quando se cobrem de cobertor cinza como a laje"? (Sousa \& Bechler, 2008, p. 401). Quantos pontiagudos objetos

\footnotetext{
${ }^{11}$ Étienne Souriau (Lille, 1892 - Paris, 1979), filósofo francês especialista em Estética.
} 
metálicos já colocamos debaixo dos viadutos para fazer desaparecerem esses corpos que se atiram na calçada, "grudando pele e concreto até não descolar"? (Sousa \& Bechler, 2008, p. 401).

A presença de pessoas em situação de rua no cenário urbano incomoda tanto quanto um elefante na cidade, pois confronta lógicas balizadoras dos modos hegemônicos de ver e viver as/nas cidades. Desde o Barão de Haussmann ${ }^{12}$, utilizando de seu "princípio social higienizador" (Leite, 2002, p. 115), norteiam as expectativas sobre as cidades assentes em planificações ordenadas, em limpezas que não se restringem ao que pode vir a ser descartável. A exemplo disso, o jornalista e doutor em ciência política Leonardo Sakamoto publicou em seu blog um texto que tratava de pessoas em situação de rua e sua permanência na cidade. $\mathrm{O}$ autor faz o seguinte relato:

Um edifício em obras na região central de São Paulo instalou gotejadores de água em sua marquise para gerar uma chuva artificial e espantar usuários de drogas que frequentavam a fachada. A administração municipal, consultada em reportagem do Jornal Nacional, da TV Globo, disse que molhar os 'pedestres' era inaceitável e que medidas seriam tomadas. Vizinhos do prédio pinga-pinga afirmaram ter gostado da ideia e pensam em copiá-la para garantir mais 'higiene e segurança'. Já escrevi aqui que São Paulo está se aprimorando na arquitetura da exclusão. Retomo o que havia dito antes. O tema não é exatamente novo e ocupou espaço na mídia quando o então prefeito José Serra resolveu implantar no complexo viário da avenida Paulista, a mais conhecida e importante da cidade, as chamadas rampas antimendigo - grandes blocos de concreto que impedem o povo de rua de montar sua casinha imaginária para se proteger do tempo e do mundo. E proteger, dessa forma, a 'gente de bem' que estaria sendo assaltada durante as longas pausas dos congestionamentos. ... As obras que estão revitalizando (sic) a região chamada de Cracolândia têm expulsado os moradores da região. Para onde vão? E isso importa?! Contanto que fiquem longe dos concertos da Sala São Paulo, do acervo do Museu da Língua Portuguesa e das exposições da Estação Pinacoteca, ótimo. No caso do prédio-que-chove os usuários de drogas não foram muito longe: mudaram-se para $o$ outro lado da rua ... Reformas já foram feitas no Centro de São Paulo para tirar ou vazar a marquise de prédios. Ganha um doce se alguém adivinhar para quê (Sakamoto, 2009).

Outro exemplo que traduz bem essa lógica higienista contra pessoas em situação de rua é o comentário do então vereador José Paulo Carvalho de Oliveira (PTdoB), da cidade de Piraí, Rio de Janeiro, no dia 8 de outubro de 2013, em uma discussão sobre os 25 anos da Constituição Federal. Nas palavras do vereador, "mendigo não tem que votar. Mendigo não faz nada na vida. Ele não tem que tomar atitude nenhuma. Aliás, acho que deveria até virar ração para peixe" ('Mendigo deveria virar. .., 2013).

Também emblemático é o caso dos experimentos realizados com animais pelo Instituto Royal na cidade de São Roque, interior de São Paulo. As notícias afirmavam que os testes realizados em animais, principalmente cachorros da raça beagle, ocorriam sem as autorizações necessárias. Algumas pessoas, anonimamente, pronunciaram-se nas redes sociais repugnando a "barbárie contra os animais, porém manifestavam o desejo de que os testes passassem a ser realizados em mendigos, presidiários ou moradores de rua" (Barros, 2014, p. 161).

Mais recentemente, no dia 27 de fevereiro de 2019, uma mulher em situação de rua, grávida, teve seu corpo queimado com etanol por dois homens que passavam por debaixo do viaduto da Caxangá, na zona Oeste de Recife, local em que ela dormia (Moradora de rua..., 2019).

Estes e tantos outros movimentos higienistas presentes nas cidades brasileiras em relação às pessoas em situação de rua não são recentes. No Código Criminal do Império, datado de 1830, a chamada mendicância já era criminalizada. Variava "de prisão simples, ou com trabalho, segundo o estado das forças do mendigo, por oito dias a um mez" (Lei de $16 \mathrm{de}$ dezembro de 1830,1831 ) a pena para quem violasse os artigos do código, dentre os quais chamamos a atenção para os artigos 295 e 296 do capítulo IV, intitulado "Vadios e Mendigos":

12 O Barão Georges Haussman foi prefeito da cidade de Paris, na França, entre os anos de 1853 e 1970, e ficou conhecido pela reforma urbanística radical que realizou naquela cidade, expulsando do centro os trabalhadores parisienses, obrigando-os a ocupar os subúrbios da urbe. 
Art. 295. Não tomar qualquer pessoa uma occupação honesta, e util, de que possa subsistir, depois de advertido pelo Juiz de Paz, não tendo renda sufficiente.

Art.296. Andar mendigando:

$1^{\circ}$ Nos lugares, em que existem estabelecimentos publicos para os mendigos, ou havendo pessoa, que se offereça a sustental-os.

$2^{\circ}$ Quando os que mendigarem estiverem em termos de trabalhar, ainda que nos lugares não hajam os ditos estabelecimentos.

$3^{\circ}$ Quando fingirem chagas, ou outras enfermidades.

$4^{\circ}$ Quando mesmo invalidos mendigarem em reunião de quatro, ou mais, não sendo pai, e filhos, e não se incluindo tambem no numero dos quatro as mulheres, que acompanharem seus maridos, e os moços, que guiarem os cegos (Lei de 16 de dezembro de 1830, 1831).

Essas vidas "mendigas", "inválidas" e "vadias" parecem ser descartáveis, algumas sequer valem a pena, como nos lembra Judith Butler (2015). Ao problematizar sobre vidas precárias e as que são passíveis ou não de luto, a autora nos adverte sobre a urgência de nos questionarmos a respeito da forma com que apreendemos uma vida e, quando da precariedade dela, a obrigação que a nós é imposta. Segundo Butler (2015):

Devemos nos perguntar em que condições torna-se possível apreender uma vida ou um conjunto de vidas, como precária, e em que condições isso se torna menos possível ou mesmo impossível. É claro, não se deduz daí que se alguém apreende uma vida como precária decidirá protegê-la ou garantir as condições para sua sobrevivência e prosperidade. Pode ser, como Hegel e Klein apontam, cada um à sua maneira, que a apreensão da precariedade conduza a uma potencialização da violência, a uma percepção da vulnerabilidade física de certo grupo de pessoas que incita o desejo de destruí-las (Butler, 2015, p. 15).

João Oliveira (2017) tece considerações sobre essa ideia de humanidade como condição precária presente na filosofia de Butler, e afirma que tal noção possibilita uma "crítica aos conceitos neoliberais do humano e do indivíduo como autossuficiente, eficaz e autodeterminado" (p. 36). Segundo o autor: "a partilha de uma condição de precariedade que pressupõe uma interdependência é antagônica com esses projetos político-ideológicos e assenta numa consideração da inteligibilidade do humano" (Oliveira, 2017, p. 36).

As políticas higienistas investem na assepsia das ruas, na limpeza das cidades, na exclusão das dissonâncias, independente do modo como se apresentam. Mas as diferenças insistem, resistem, afirmam suas presenças nas cidades, por vezes como meros vestígios a nos lembrar de possibilidades outras de existência. Vestígios e ruídos que se inscrevem nas esquinas escuras, em cantos esquecidos, em porções da cidade abandonadas por algumas poucas horas do dia ou por dias em semanas e meses.

à medida que vai se cristalizando esta imagem sobre o ideal de 'pureza' e 'organização' que deve permear a sociedade, forma-se também um imaginário sobre quem pode ou não pertencer a esta sociedade 'almejada'. Tal raciocínio volta-se contra as pessoas que não obedecem ao padrão estabelecido, considerando-as um obstáculo ao alcance desta ordem e, conseqüentemente, excluindo-as. Dizendo de forma mais clara: sob esta ótica da 'pureza', é justificável descartar setores inteiros da sociedade, tentando privá-los de voz ativa e reduzindo seus papéis sociais e sua dimensão na vida cotidiana da cidade (Kuster, 2008, p. 2).

Os elefantes de nossas cidades - pessoas que habitam a urbe em situação de violação de direitos são também como o home sacer $^{13}$, conceito apresentado por Giorgio Agamben para se referir àquele que "tem a vida que não merece ser vivida. A vida nua" (Barros, 2014, p. 159). A respeito dessa condição do homo sacer, Agamben (2007) acrescenta:

O homo saceré uma contradição, é algo paradoxal, pois ele é, ao mesmo tempo, sagrado e impuro. É o ser que não está entre as divindades e nem entre os homens comuns. Algo (alguém) ambíguo; que é pelo que não é. O homo sacer caracteriza-se

${ }^{13}$ O homo sacer é uma figura presente no direito romano arcaico, cuja "vida humana é incluída na ordem jurídica pela sua exclusão, ou seja, pela sua absoluta matabilidade" (Barros, 2014, p. 159). 
por ser 'uma pessoa [que] é simplesmente posta para fora da jurisdição humana sem ultrapassar para a divina (Agamben, 2007, p. 23).

Protocolo Elefante evidencia a inseparabilidade da criação da peça com o trabalho de cada artista e seu corpo, com a relação deles com cada objeto, com a montagem de cada cena, com a composição de suas vidas, de sua história, com aquilo que se pretende inventar. Não há montagem do espetáculo sem o imbricamento com cada uma daquelas vidas que assistimos no palco, da experiência delas, de seus processos de existência, de suas relações com as pessoas, com o mundo que as cerca.

Nesse sentido, podemos pensar em como as vidas das pessoas em situação de rua se compõem, a partir das suas relações com a cidade. Por vezes seus corpos são tidos como dejetos, perigosos, inúteis, por outras esses corpos são necessários para a manutenção da ordem política e econômica vigente. A respeito disso, Karine Carneiro (2019) aponta que muitos espaços urbanos onde as pessoas em situação de rua se concentram não foram simplesmente tomados por essa população, mas sim deixados que se transformassem em lugares que acolhem populações historicamente invisibilizadas, majoritariamente relacionados à implementação de políticas públicas.

os conjuntos de ações conduzidas pelos poderes públicos locais têm buscado, menos arcar com as dívidas históricas vinculadas à exploração e à sujeição dos corpos que deles se apropriam e mais como oportunidade para que a elite controladora da produção dos espaços da cidade possa dar continuidade aos processos homegeneizantes de transformação empreendedorista sobre o tecido urbano. A terra urbana degradada e seu entorno podem ser comprados a baixo preço e, após investimentos, a médio e longo prazo, trazem grandes retornos financeiros. Nesse âmbito, os corpos dos moradores de rua, considerados anormais tanto como indivíduos como na dimensão da população, passam a ser compreendidos não mais como um problema para a cidade e seus espaços, mas como uma parte da lógica de destruição criativa do espaço político-econômico que se espraia nos tecidos urbanos das cidades. Tornam-se corpos úteis e tão antigos quanto a história dos próprios centros urbanos. Ou seja, ao mesmo tempo que temporariamente impedem, justificam e renovam as possibilidades de investimentos na lógica neoliberal. (Carneiro, 2019, p. 59).

Outro conceito que nos permite pensar essas tensões entre as pessoas em situação de rua e a cidade é o de necropolítica, cunhado pelo filósofo camaronês Achille Mbembe. Ao analisar o papel do Estado em relação à violação de direitos, Mbembe esclarece que alguns tipos de violência são legitimados pelo próprio Estado, que decide e reforça o que é ou não uma vida possível de existir. A necropolítica separa a pessoa de seu contexto e a entrega a uma situação de total desamparo e proteção, fazendo-a morrer aos poucos, e promove "matanças invisíveis" (Mbembe, 2018, p. 49).

A necropolítica, portanto, tem a ver com a capacidade do Estado de "definir quem importa e quem não importa, quem é 'descartável' e quem não é" (Mbembe, 2018, p. 41). As políticas higienistas da cidade, voltadas às pessoas em situação de rua, inscrevem-se, por conseguinte, como necropolítica, um protocolo de morte criado à semelhança do protocolo anunciado do elefante.

\section{Considerações finais}

Ao final do espetáculo uma luz azul inundou o teatro, acompanhada de uma nuvem de fumaça que criava a ilusão de uma espécie de aurora boreal a percorrer aqueles corpos-elefantes em cena. Além dos bastões de metal, as(os) artistas traziam como adereço cordas que compunham movimentos outros, a recortar aquele azul que nos invadia os olhos.

Difícil encontrar palavras para descrever tal experiência com a intensidade devida. Naquele momento a espectadora/pesquisadora transitou de forma diferente por aquele espaço, andou de formas outras pelo território do elefante. Uma experiência estética tem como tarefa essencial promover afetamentos que nos interpelem e nos permitam questionar o que nos rodeia, e isso foi o que Protocolo Elefante provocou.

O fim da peça, de certa forma, anunciava a morte do elefante, e a agonia do animal provocou questionamentos à nossa responsabilidade, como cidadãos(ãs), sobre as paisagens urbanas que ajudamos a compor. Que dever nos cabe diante da violação de direitos que sofrem as pessoas em situação de rua? Como essas existências mínimas (Lapoujade, 2017) podem ter seu direito de existir assegurado? 
O fim do espetáculo surpreendeu a todos(as). Fim-infinito, fim-inacabado: inacabamento. As(os) bailarinas(os) saíram de cena e todos esperavam por mais um ato, mais uma coreografia, mais uma partitura corporal. As luzes azuis e a fumaça continuavam a pairar sobre o público. Uns se levantaram, outros continuaram sentados, não sabiam se aplaudiam ou não. Não sabiam o que fazer. A potência de
Protocolo Elefante talvez resida justamente nesse inacabamento em direção à complexidade da vida e incerteza do que pode vir a ser. Uma peça-abismo a provocar inquietações, a tensionar certezas. A explicitar violências de protocolos que aviltam a vida de variadas maneiras, como vemos acontecer cotidianamente com pessoas em situação de rua que habitam as cidades.

\section{Referências}

'Mendigo deveria virar ração para peixe', diz vereador de Piraí, RJ. (2013, 28 outubro). Gl. https://glo.bo/379weSv

Agamben, G. (2007). Homo Sacer: O poder soberano e a vida nua I. Ed. UFMG.

Amorim, M. (2016). Cronotopo e exotopia. In Brait, B. Bakhtin: outros conceitos- chave (pp. 95114). Contexto.

Barros, J. O. (2014). A pessoa em situação de rua e a vida que não merece ser vivida. In A. P. Grinover, G. A. Almeida, M. Gustin, P. C. V. Lima, \& R. Iennaco (Orgs.), Direitos fundamentais das pessoas em situação de rua (pp. 153177). D’Plácido.

Bezerra, P. (2012). A tradução como criação. Estudos Avançados, 26(76), 4756. https://doi.org/10.1590/ S0103-40142012000300007

Brait, B. (Org.). (2016). Bakhtin: outros conceitos-chave. Contexto.

Britto, F. D. (2009). Co-implicações entre corpo e cidade: da sala de aula à plataforma de ações. In F. D. Britto, \& P. B. Jacques (Orgs), Corpocidade: debates, ações e articulações (pp. 1223). UFBA.

Britto, F. D., \& Jacques, P. B. (2009). Corpocidade: arte enquanto micro-resistência urbana. Fractal: Revista de Psicologia, 21(2), 337350. https:// periodicos.uff.br/fractal/article/view/4751

Butler, J. (2015). Quadros de guerra: quando a vida é passível de luto?. Civilização Brasileira.

Careri, F. (2013). Walkscapes: o caminhar como prática estética. Gustavo Gili.

Carneiro, K. G. (2019). Perigosos ou úteis? Os moradores de rua e a produção do espaço urbano em Belo Horizonte e Bogotá. Civitas - Revista de Ciências Sociais, 19(1), 4561. https://doi.org/10.15448/1984-7289.2019.1.30907

Cena 11. (2016). Protocolo Elefante. https://www.cenall.com.br/protocolo-elefante.

Certeau, M. (1994). A invenção do cotidiano: Artes de fazer. Vozes.

Damasceno, V. (2017). Pensar com a arte: a estética em Deleuze. Viso: Cadernos de Estética Aplicada, 11(20), 135150. http://doi.org/10.22409/1981-4062/v20i/223

Deleuze, G. (2007). Francis Bacon: Lógica da sensação. Zahar.

Deleuze, G., \& Guattari, F. (2012). Mil platôs: capitalismo e esquizofrenia. Editora 34.

Didi-Huberman, G. (2014). Sobrevivência dos vaga-lumes. Ed. UFMG.

Foucault, M. (2006). A vida dos homens infames. Ditos \& Escritos IV: Estratégia, poder-saber. Forense Universitária.

Galeano, E. (2005). O livro dos abraços. L \&PM Pocket.

Houaiss, A., \& Villar, M. S. (2009). Dicionário Houaiss da Língua Portuguesa. Objetiva.

Jacques, P. B. (2012). Elogio aos errantes. EDUFBA.

Jobim e Souza, S., \& Porto e Albuquerque, E. D. (2013). Bakhtin e Pasolini: vida, paixão e arte. In M. T. A. F. Freitas (Org.), Educação, arte e vida em Bakhtin (pp. 4768). Autêntica.

Kafka, F. (2001). A metamorfose. Editora L \&PM. (Trabalho original publicado em 1915).

Kuster, E. (2008). Outros olhos: As ru(s)gas da cidade e seu desvelamento nos discursos contemporâneos. In E. Kuster, \& R. Pechman, O chamado da cidade: ensaios sobre a urbanidade (pp. 4758). Ed. UFMG. 
Lapoujade, D. (2017). As existências mínimas. n-1 edições.

Lei de 16 de dezembro de 1830. (1831, 7 de janeiro). Manda executar o Código Criminal. http://www.planalto.gov.br/ ccivil_03/leis/lim/LIM-16-12-1830.htm

Leite, R. P. (2002). Contra-usos e espaço público: Notas sobre a construção social dos lugares na Manguetown. Revista Brasileira de Ciências Sociais, 17(49), 115134. https:/ / doi.org/10.1590/S0102-69092002000200008

Mangueira, M., \& Maurício, E. (2012). Arte, tempo e subjetividade em Gilles Deleuze. Artefilosofia, 7(13), 154166. https://periodicos.ufop.br/raf/article/view/568/524

Mbembe, A. (2018). Necropolítica. n-1 Edições.

Moradora de rua tem corpo queimado enquanto dormia embaixo de viaduto. (2019, 27 fevereiro). G1. https://glo.bo/ 3idNZqc

Oliveira, J. M. (2017). Desobediências de gênero. Devires.

Sakamoto, L. (2009). Comoexpulsardrogados, mendigoseoutrosestorvos. BlogdoSakamoto. https:/ /blogdosakamoto. blogosfera.uol.com.br/2009/06/24/como-expulsar-drogados-mendigos-e-outros-estorvos/

Santos, M. (1994). Técnica, espaço e tempo: globalização e meio técnico-científico informacional. Hucitec.

Santos, N. A. (2010). Arte e saúde mental: em cartaz o teatro da loucura [Dissertação de Mestrado, Pontifícia Universidade Católica de Minas Gerais]. SIB PUC Minas. http://www.biblioteca.pucminas.br/teses/Psicologia SantosNA_1.pdf

Sousa, E. L. A., \& Bechler, J. (2008). Labirintos na cidade contemporânea. Psicologia: Ciência e Profissão, 28(2), 390403. https:// doi.org/10.1590/S1414-98932008000200013

Tv em Cartaz. (2017, 29 de março). Entrevista: Protocolo Elefante. https://www.youtube.com/watch?v=SPrR66Y0lsE

Vigotski, L. S. (1999). A tragédia de Hamlet, príncipe da Dinamarca. Martins Fontes.

Zanella, A. V., \& Furtado, J. R. (2012). Resistir. In T. M. G. Fonseca, M. L. Nascimento, \& C. Maraschin (Orgs.), Pesquisar na diferença: um abecedário (pp. 205206). Sulina.

\section{Natália Alves dos Santos}

Psicóloga, doutora em Psicologia Social e Cultura pelo Programa de Pós-Graduação em Psicologia da Universidade Federal de Santa Catarina (UFSC), Florianópolis - SC. Brasil.

E-mail: santosnatalia.alves@gmail.com

(1) https://orcid.org/0000-0001-8552-1208

\section{Andréa Vieira Zanella}

Docente permanente do Programa de Pós-Graduação em Psicologia da Universidade Federal de Santa Catarina (UFSC), pesquisadora do CNPq, Florianópolis - SC. Brasil.

E-mail: a.zanella@ufsc.br

(1) https://orcid.org/0000-0001-8949-0605

Agradecimentos e fonte de financiamento:

O presente trabalho foi realizado com apoio da Coordenação de Aperfeiçoamento de Pessoal de Nível Superior (CAPES). Código de Financiamento 001.

Endereço para envio de correspondência:

Universidade Federal de Santa Catarina, Campus Trindade, Centro de Filosofia e Ciências Humanas (CFH),

Departamento de Psicologia. Rua Roberto Sampaio Gonzaga, s/n, Trindade. CEP: 88040-970. Florianópolis - SC. Brasil. 
Recebido 06/04/2019

Aceito 03/04/2020

Received 04/06/2019

Approved 04/03/2020

Recibido 06/04/2019

Aceptado 03/04/2020

Como citar: Santos, N. A., Zanella, A. V. (2021). Arte, corpo, cidade: sobre elefantes e pessoas em situação de rua. Psicologia: Ciência e Profissão, 41, 1-13. http://doi.org/10.1590/1982-3703003222369

How to cite: Santos, N. A., Zanella, A. V. (2021). Art, body, city: on elephants and homeless people. Psicologia: Ciência e Profissão, 41, 1-13. http://doi.org/10.1590/1982-3703003222369

Cómo citar: Santos, N. A., Zanella, A. V. (2021). Arte, cuerpo, ciudad: sobre elefantes y personas en situación de calle. Psicologia: Ciência e Profissão, 41, 1-13. http://doi.org/10.1590/1982-3703003222369 